AperTO - Archivio Istituzionale Open Access dell'Università di Torino

\title{
Emotion Regulation and Defense Mechanisms
}

\section{This is the author's manuscript}

Original Citation:

Availability:

This version is available http://hdl.handle.net/2318/1508669

since 2015-07-31T21:03:40Z

Published version:

DOI:10.1027/1614-0001/a000151

Terms of use:

Open Access

Anyone can freely access the full text of works made available as "Open Access". Works made available under a Creative Commons license can be used according to the terms and conditions of said license. Use of all other works requires consent of the right holder (author or publisher) if not exempted from copyright protection by the applicable law. 


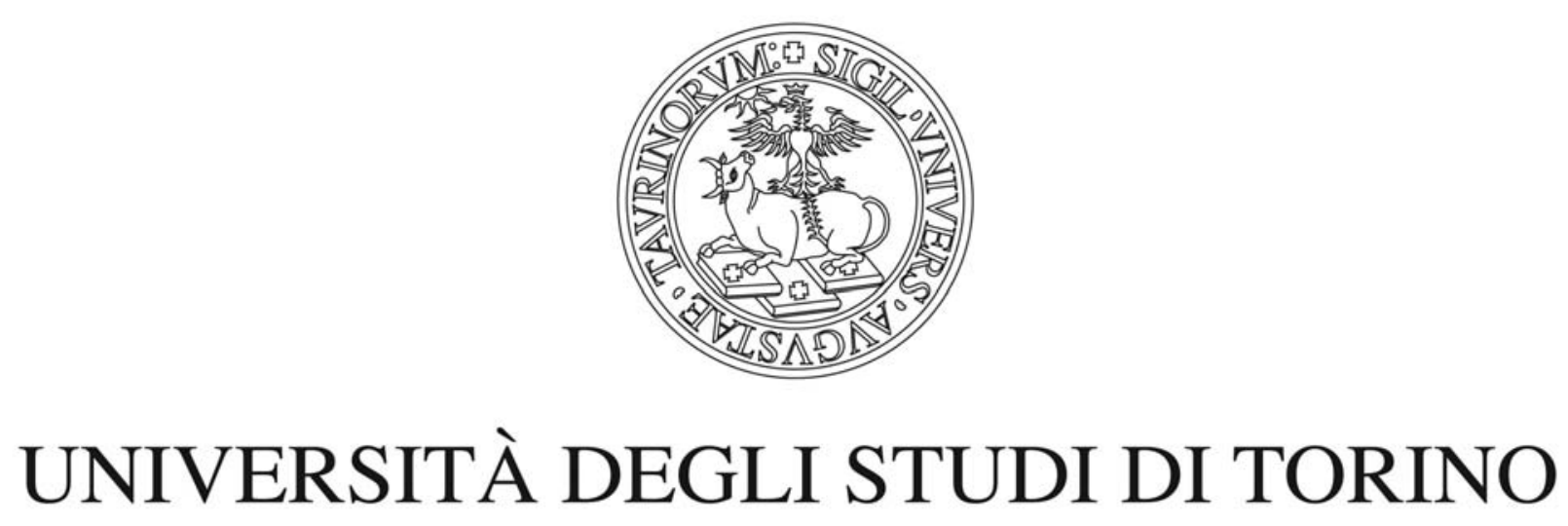

This is an author version of the contribution published on:

Questa è la versione dell'autore dell'opera:

Sala, M.N., Testa, S., Pons, F., \& Molina, P. (2015), Emotion Regulation and Defense

Mechanism, Journal of Individual Differences, 36 (1), 19-29 [DOI: 10.1027/1614-0001/a000151]

The definitive version is available at:

La versione definitiva è disponibile alla URL:

http://econtent.hogrefe.com/doi/pdf/10.1027/1614-0001/a000151 


\section{Emotion Regulation and Defense Mechanisms}

\section{Abstract}

This study examined the relations between emotion regulation and defense mechanisms as assessed through self-report questionnaires. Participants were 314 undergraduate students at the University of Turin (Faculty of Agricultural Studies, School of Sport and Exercise Sciences and Faculty of Psychology). Correlational analysis identified several associations between emotion regulation strategies and defense mechanisms. A second-order factor model was tested in which each of the dimensions assessed by the defense mechanisms and emotion regulation instruments was assigned to either an adaptive or maladaptive latent dimension. The results suggested that the dimensions of adaptiveness and maladaptiveness may represent a key link between emotion regulation and defense mechanisms.

\section{Keywords}

Emotion Regulation, Defense Mechanisms 


\section{Emotion Regulation and Defense Mechanisms}

This research examined the relations between emotion regulation and defense mechanisms.

Emotion regulation consists of all processes, conscious and not conscious, internal or external, used to increase, maintain, or decrease positive and negative emotions. Such processes influence the type of the emotion experienced, the time at which it occurs and how it is perceived and expressed by the subject; and they are implicated in personality, emotional, cognitive, and social development (Gross, 2002).

Cramer (2008; 2012) defined defenses as mental processes, also present in normal personality, that alter the perception of a disturbing external event or a disruptive inner state with the aim to protect the individual from excessive anxiety or other negative emotions arising from the perception of these stimuli. Although defense mechanisms have been primarily investigated in the contest of clinical research, recently their role in self-regulation, adjustment, and adaptation has been emphasized (Diehl, Chui, Hay, Lumley, Grühn, \& Labouvie-Vief, 2014).

\section{Differences and Similarities in Emotion Regulation and Defense Mechanisms}

Emotion regulation and defenses are both processes aiming to manage individual's internal states. Nonetheless, they represent two different constructs.

Firstly, defense mechanisms and emotion regulation fall under two very different theoretical areas. On the one hand, defenses arise and are present in the framework of psychoanalytic theory (A. Freud, 1936) and this concept is largely used in the mainstream of clinical psychology and psychiatry, as the inclusion in DSM (APA, 1994) attests. On the other hand, although the emotion regulation origin is recognized to be linked to defense mechanisms (Gross, 2002), the actual empirical research on emotion regulation originated in the field of developmental psychology (Thompson, 1994). Moreover, the construct of emotion regulation is currently largely present in developmental psychology research and in other research areas that are distant from the psychoanalytic perspective (e.g.: cognitive psychology and neuropsychology; Koole, 2009). Secondly, defenses have been studied as individual stable differences focused on negative emotional experiences and particularly anxiety, arising from a psychological disequilibrium, associated with the perception of an external or internal stressor. Conversely, emotion regulation has been studied as a set of processes directed to both positive and negative emotions (Gross, 1998a; Cramer 1998). In this regard, Gross and Thompson (2007; Gross, 1998a) analysed the differences between emotion regulation and defense mechanisms: the authors stated that, while emotion regulation strategies are oriented towards the management of emotions including anger, 
sadness or happiness, defense mechanisms are directed at the regulation of impulses such as those related to aggression or sex. Emotions are experienced more flexibly and they have a broader range of potential objectives; impulses are more rigid in nature and are directed at a smaller number of goals. Moreover, while defense mechanisms aim to protect the individual from excessive anxiety, emotion regulation is not only directed at decreasing the effect of the emotions, but it can also sustain and prolong them (Calkins \& Hill, 2007). Another important difference between the two constructs refers to the level of consciousness of the processes implicated. While emotion regulation processes can either be conscious or unconscious (Gross, 2002), defenses have been described as typically unconscious processes (Cramer, 1998). Nevertheless, the more adaptive defense mechanisms, reported in Vaillant’s (1997) and Perry’s (1990) classifications, present some exceptions, for example the suppression is a defense mechanism that has been described as involving a conscious intention to exclude some thoughts or perceptions resulting in anxiety.

Despite those differences the two constructs present some important similarities. Firstly, Gross stated that both these constructs have to do with the management of affect: the author described the broader construct of Affect Regulation which comprises both defense mechanisms and emotion regulation. Affect is a superordinate category that includes different states: stress, moods, emotions and impulses. Like emotions, impulses have a valence, and they direct and influence behaviour (Gross, 1998a). Secondly, they both are involved in the normative development (Cramer, 1991) and play an important role in mental health: the two constructs have been included in the definition of psychological well being (e.g.: Gratz \& Roemer, 2004; Cramer 2008). Furthermore, both emotion regulation and defense mechanisms are classified as possibly semantically interconnected systems of strategies: the definition of some emotion regulation strategies (Garnefski, et al., 2002) presents evident similarities with the definition of some of the defences described by Perry (1990); the emotion regulation strategy named rumination and the defense mechanism named intellectualization could be considered a good example. Additionally, both emotion regulation and defense mechanisms could be described as having adaptive/maladaptive dimensions. For example, the model proposed by Westen and Balgov (2007) defines emotion regulation as a superordinate category divided into two dimensions: one ranging from adaptive to maladaptive, and the other from implicit to explicit poles. In this model, the two constructs are not independent because defense mechanisms are included in the broader construct of emotion regulation: specifically, defenses are considered to be the implicit component of emotion regulation, which can range from adaptive to maladaptive. In any case, the model sees both emotion regulation and defense mechanisms as positioned on an adaptive-maladaptive continuum. Defenses are typically classified into single processes ranging from adaptive to maladaptive (Vaillant, 1994; 
Perry, 1990; Lingiardi \& Madeddu, 2002), whereas emotion regulation strategies have not been commonly categorized as adaptive and maladaptive (Gross, 1998b). However, there is an ongoing debate about the importance of defining specific emotion regulation strategies as adaptive or maladaptive (Bonanno, 2001); research underlined that there are important individual differences in the use of emotion regulation and that the strategies employed may be more or less adaptive (Garnefsky, van den Kommer, Kraaij, Teerds, Legerstee, \& Onstein, 2002); moreover, recent studies have distinguished between adaptive and maladaptive emotion regulation strategies in investigating the role of emotion regulation in psychopathology (Aldao \& Nolen-Hoeksema, 2012).

\section{The present study}

Although different theoretical models have been proposed in order to conceptualize the relationship between emotion regulation and defenses (e.g.: Gross, 1998a; Westen \& Blagov, 2007), there is a lack of empirical studies investigating this relation. Moreover, a limited amount of researches has been conducted using instruments to measure both constructs (Ellison \& Levy, 2012). This work aimed to investigate the relationships between emotion regulation and defense mechanisms; considering the lack of research on the topic, this goal constitutes an innovative point of our research.

In the present study, we set out to analyse commonalities and differences between the two constructs evaluated using self-report instruments. We chose to use self-report questionnaires because they allowed us to obtain data about the two constructs assessed through the same type of instrument. Self-reports have been largely used in research on individual differences in both emotion regulation and defense mechanisms (e.g.: Drapeau, Thompson, Petraglia, Thygesen, \& Lecours, 2011a; English \& John, 2013; Yu, 2011; Diehl, et al., 2014). Although the definition of defense mechanisms emphasizes their unconscious aspects, empirical research on defenses with self-report inventories assumed that individuals can be aware of their residuals (Ruuttu, Pelkonen, Holi, Karlsson, Kiviruusu, Heilä, . . . Marttunen, 2006). Furthermore, literature underlined the validity of self-report instruments to investigate defenses (e.g.: Hyphantis, Goulia, Floros, Iconomou, Pappas, Karaivazoglou, \& Assimakopoulos, 2011; Segal, Coolidge, \& Mizuno, 2007).

The first aim of the study was to investigate the relationships between the specific strategies of emotion regulation and the specific defense mechanisms assessed by our research instruments. We expected to find an association between emotion regulation strategies involving a reappraisal of the situation and efforts to understand feelings and emotional states, and defenses that permit awareness of reality and feelings. Similarly, we expected to find links between emotion regulation strategies involving the tendency to direct negative emotions against others or to think incessantly 
about negative situations, and defenses that influence and distort the perception of reality. The second aim of the study was to verify whether the dimensions of adaptiveness and maladaptiveness could represent a valid link between emotion regulation and defense mechanisms. To this end, a second-order factor model was tested. In this model, each of the dimensions assessed by the defense mechanisms and emotion regulation questionnaires was assigned to an adaptive or maladaptive latent dimension specific to that questionnaire (first-order factors) while the questionnaire-specific adaptation and maladaptation factors were related in turn to a broader latent dimension of adaptive or maladaptive strategies (second-order factors).

\section{Method}

\section{Participants}

The sample comprised 314 undergraduate students (50\% female) attending the University of Turin (Faculty of Agricultural Studies, School of Sport and Exercise Sciences and Faculty of Psychology; the psychology students were in the first semester of their first year). Participants were aged between 18 and 26 years $(M=20.67$; $\mathrm{sd}=1.52), 45.5 \%$ had a job, and $52.9 \%$ were in a relationship. All were native Italian speakers. Questionnaires were presented in randomized order during a single session.

\section{Measures}

All respondents completed a battery of instruments composed of the Defense Style Questionnaire (DSQ; San Martini, Roma, Sarti, Lingiardi, \& Bond, 2004), the Emotion Regulation Questionnaire (ERQ; Balzarotti, John, \& Gross, 2010), the Cognitive Emotion Regulation Questionnaire (CERQ; Garnefski, Kraaij, \& Spinhoven, 2002) and the Difficulties in Emotion Regulation Scale (DERS; Gratz \& Roemer, 2004). These instruments were chosen considering they have been largely adopted in research in both the fields of defense mechanisms and emotion regulation. In particular, the DSQ, was chosen because built upon Vaillant's model of defense mechanisms and for its recognized validity in assessing defenses (e.g.: San Martini et al., 2004 ; Andrews, Singh, M., \& Bond, 1993; Watson \& Sinha, 1998); moreover, this instrument represents the most widely used self-report method for assessing ego defense mechanisms (Bond, 2004). The three instruments evaluating emotion regulation were chosen because they focus on different processes associated to the ways in which emotions are regulated by the individuals: the antecedent and response focused processes for the ERQ, the several cognitive strategies evaluated by the CERQ and the different type of difficulties in the regulation of emotions evaluated by the DERS. These characteristics permitted us to collect information about several processes associated to 
emotion regulation. The availability of a wide range of processes was fundamental to the purpose of associating them to the different defense mechanisms. Questionnaires’ reliability coefficients are reported in Table 1.

Table 1 Descriptive statistics

\begin{tabular}{|c|c|c|c|c|}
\hline Dimensions & Mean & SD & \multicolumn{2}{|c|}{ Cronbach’s Alpha } \\
\hline \multicolumn{5}{|l|}{ DSQ } \\
\hline Maladaptive Style & 3.04 & 0.68 & .80 & \\
\hline Image-Distorting Style & 3.37 & 0.73 & .72 & \\
\hline Self sacrificing Style & 3.14 & 0.72 & .60 & \\
\hline Adaptive Style & 4.10 & 0.69 & .60 & \\
\hline ERQ & & & & (Balzarotti, et all 2010) \\
\hline Reappraisal & 4.49 & 1.08 & .77 & .80 \\
\hline Suppression & 3.34 & 1.17 & .62 & .64 \\
\hline CERQ & & & & (Gamefski,et.al 2002) \\
\hline Self Blame & 2.86 & 0.70 & .60 & .68 \\
\hline Acceptance & 3.34 & 0.77 & .54 & .73 \\
\hline Rumination & 3.43 & 0.77 & .61 & .79 \\
\hline Positive Refocusing & 3.02 & 0.99 & .83 & .78 \\
\hline Refocus on Planning & 3.98 & 0.74 & .73 & .76 \\
\hline Positive Reappraisal & 3.60 & 0.86 & .75 & .76 \\
\hline Putting into Perspective & 3.67 & 0.86 & .73 & .76 \\
\hline Catastrophizing & 2.47 & 0.87 & .71 & .74 \\
\hline Blaming Others & 2.25 & 0.80 & .71 & .73 \\
\hline DERS & & & & (Gratz, et al 2003) \\
\hline Nonacceptance of Emotional Response & 2.20 & 0.82 & .79 & .85 \\
\hline $\begin{array}{l}\text { Difficulties engaging Goal directed } \\
\text { behaviour }\end{array}$ & 3.10 & 0.88 & .77 & .89 \\
\hline Impulse Control difficulties & 2.29 & 0.90 & .85 & .86 \\
\hline Lack of emotional awareness & 2.72 & 0.67 & .60 & .80 \\
\hline $\begin{array}{l}\text { Limitated access to emotion regulation } \\
\text { strategies }\end{array}$ & 2.31 & 0.77 & .77 & .88 \\
\hline Lack of Emotional Clarity & 2.46 & 0.86 & .84 & .84 \\
\hline
\end{tabular}

Defense Style Questionnaire (DSQ; San Martini et al., 2004). This instrument evaluates defense mechanisms through self-appraisals of conscious derivatives of defenses, specifically measuring behaviours, attitudes, and beliefs that are reflective of defense mechanisms (Segal, et al., 2007). The DSQ Italian version is an 88-item instrument assessing four defensive styles 
conceptualized along a continuum of adaptiveness/maladaptiveness, the answer categories range from 1 (strongly disagree) to 9 (strongly agree). The Maladaptive style includes defenses such as projection, acting out and regression; the Image-Distorting style comprehends defenses such as omnipotence and splitting; The Self-Sacrificing style includes defenses such as reaction formation and inhibition; while the Adaptive style covers defenses such as task orientation, affiliation and sublimation.

Emotion Regulation Questionnaire (ERQ; Balzarotti, et al., 2010; Sala, Molina, Abler, Kessler, Vanbrabant, \& van de Schoot, 2012). The instrument comprises 10 items assessing two regulatory strategies: Reappraisal, an antecedent-focused strategy, involving cognitive change that modifies the emotional impact of a situation; Suppression, a response-focused strategy that modulates emotional response via the inhibition of ongoing emotion-expressive behaviour. The answer categories range from 1 (strongly disagree) to 7 (strongly agree).

Cognitive Emotion Regulation Questionnaire (CERQ; Garnefski et al., 2002). The questionnaire assesses what people think after experiencing a negative event via 36 items measuring the following cognitive and conscious emotion regulatory strategies: Self-Blame, that is to say, thoughts of blaming yourself for what you have experienced; Acceptance, or thoughts of being resigned to what has happened; Rumination, or incessant thinking about the feelings and thoughts associated with the negative event; Positive Refocusing, or thinking of other, pleasant matters instead of the negative event; Refocus on Planning, or thinking about what steps to take in order to deal with the event; Positive Reappraisal, or thinking of attaching a positive meaning to the event in terms of personal growth; Putting into Perspective or thoughts of playing down the seriousness of the event in comparison to other events; Catastrophizing, or explicitly emphasizing the terror of the experience; Other-Blame, or thoughts blaming others for the negative experience. The answer categories for each of the items range from 1 (almost never) to 5 (almost always).

Difficulties in Emotion Regulation Questionnaire (DERS; Gratz \& Roemer, 2004). The 36 items of this instrument reflect difficulties affecting a number of dimensions of emotion regulation: Non-Acceptance of Emotional Response; Difficulty in Engaging in Goal-Directed Behaviour; Impulse Control Difficulties; Lack of Emotional Awareness; Limited Access to Emotion Regulatory Strategies; Lack of Emotional Clarity. Responses range from 1 (almost never) to 5 (almost always).

In the factor analysis, only the Maladaptive and Adaptive subscales of the DSQ were included, while each of the dimensions of the CERQ and DERS questionnaires and each item of the ERQ were classified as either adaptive or maladaptive on the basis of theoretical considerations and the results of previous research. Specifically, all the DERS dimensions were classified as 
maladaptive; items measuring suppression and reappraisal in the ERQ questionnaire were classified as maladaptive and adaptive, respectively; of the CERQ subscales, Acceptance, Positive Refocusing, Refocus on planning, Positive Reappraisal, and Putting into Perspective, were classified as adaptive strategies, while Self-Blame, Rumination, Catastrophizing and Other-Blame were classified as maladaptive strategies, as suggested by the authors (Garnefski et al., 2002).

\section{Data Analysis}

After conducting the descriptive analysis and examining the reliability of each of the instruments, the relationships between the dimensions assessed by the Defense Style Questionnaire and the subscales of each of the three emotion regulation instruments were analysed by means of Pearson’s correlation coefficients.

Exploratory factor analysis (EFA) was then carried out to explore the fit of the classification of items and subscales into adaptive or maladaptive strategies and consequently to eliminate poorly fitting indicators. Two confirmatory factor models (CFA, Lisrel 8.72; Jöreskog \& Sörbom, 1996) were estimated on the remaining indicators, one with first-order factors only (the seven first-order factors in Fig. 1) and the other with the addition of second-order factors. Our expectation was that the second-order factor model would display equally good fit to the first-order model. In both models ERQ items were aggregated in 3 and 2 parcels, respectively for the adaptive and maladaptive subscale ${ }^{1}$. The EFA was performed using the principal axis factoring method of extraction (with oblimin rotation), while the CFA was carried out via robust ML estimation (of the covariance matrix), given that the observed variables were not multivariate normally distributed. The following criteria were used to evaluate EFA solutions: REPR, or the percentage of residuals (i.e. differences between the observed and model-reproduced correlations) over $|0.05|$ less than or equal 10\% (Molinengo \& Testa, 2010), Cattell’s scree test and parallel analysis (as implemented in O'Connor, 2000). CFA model fitting was assessed by RMSEA $<.08$; CFI $>.95$; SRMR $<.08$ (Browne \& Cudeck, 1993; Hu \& Bentler, 1995; 1999), and the Satorra-Bentler scaled difference chi-square test (Satorra \& Bentler, 2001).

\footnotetext{
${ }^{1}$ Items were parceled to homogenise ERQ indicators to those of the other instruments that were made of subscales and not of single items. Previous research and also the EFA results in this study clearly evidenced the unidimensionality of reappraisal and suppression items, allowing their parceling (Bandalos, Finney, 2001). Each parcel was formed by the two nearest items in the questionnaire.
} 


\section{Results}

\section{Correlational analysis}

Relations between scores on the DSQ scales and scores on the subscales of three emotion regulation questionnaires were explored.

There was a significant positive correlation between adaptive style (DSQ) and Reappraisal (ERQ; Table 2); moreover, Reappraisal (ERQ) was weakly positively correlated with Image Distorting style (DSQ) and weakly negatively correlated with Self Sacrificing style (DSQ). Furthermore, Suppression (ERQ) was significantly positively correlated with Maladaptive, Image Distorting and Self Sacrificing styles (DSQ).

Table 2 Pearson's correlations

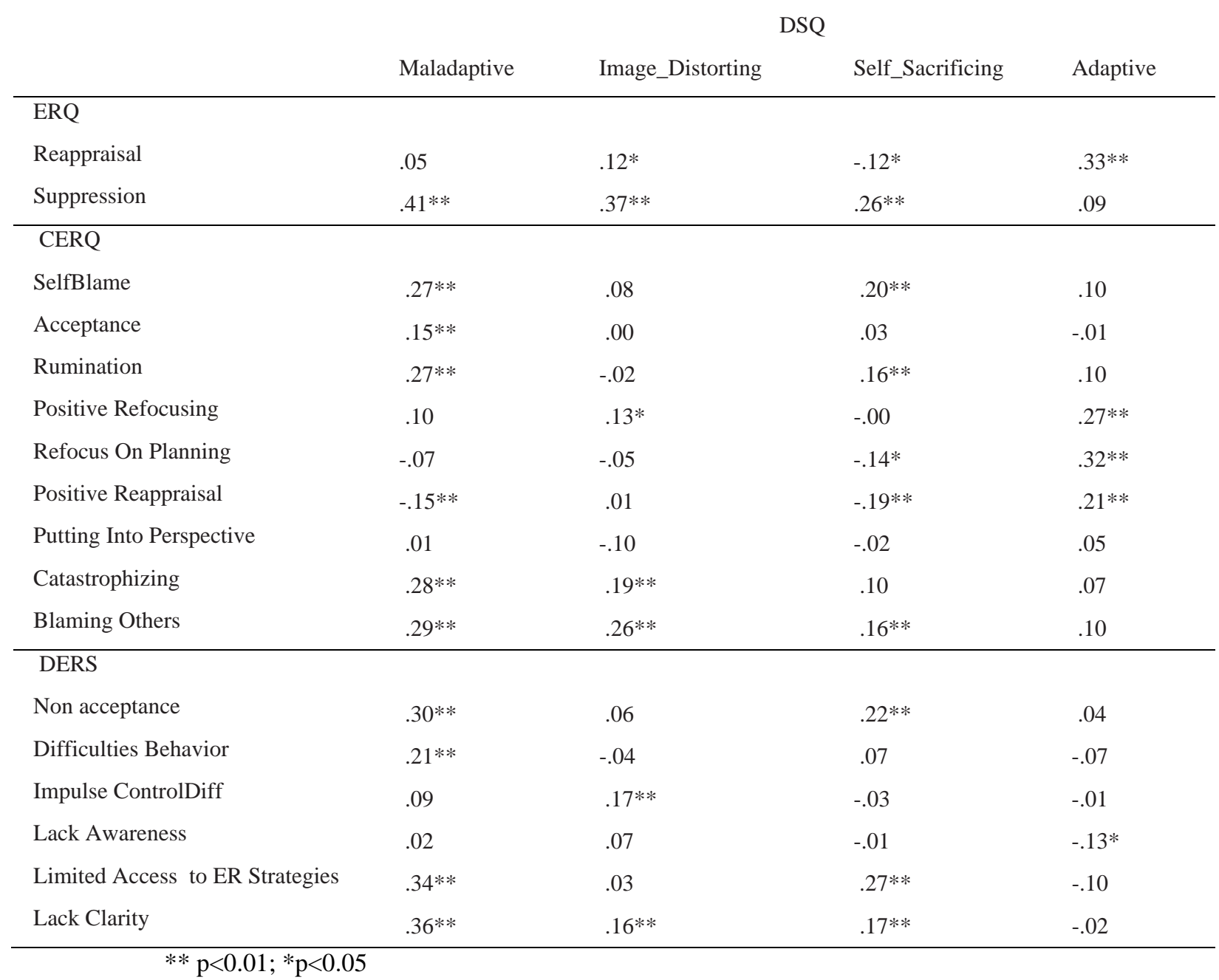

As shown in Table 2, a positive correlational relationship was confirmed between Adaptive style on the one hand and the CERQ subscales of Positive Refocusing, Refocus on Planning and Positive Reappraisal on the other. This finding shows that both DSQ and CERQ questionnaires tap into positive resources for the management of feelings. However, the correlation pattern did not 
include the Putting into Perspective scale. A further significant positive correlation was found between Self Sacrificing defense style (DSQ) and Self-Blame (CERQ), and low but significant positive correlations between Self Sacrificing (DSQ) and the CERQ scales of Rumination and Other-Blame. Self-sacrificing style (DSQ) was also negatively correlated with Refocus on Planning and Positive Reappraisal scales (CERQ). Image Distorting style (DSQ) was correlated with the Catastrophizing and Other-Blame scales of the CERQ; moreover it resulted weakly correlated with Positive Refocusing. Finally, Maladaptive style was positively and significantly correlated with the CERQ Self-Blame, Acceptance, Rumination, Catastrophizing and Other-Blame scales, with a weakly negative but significant correlation between Maladaptive style and Positive Reappraisal. With regard to the DERS scales, there was only a low negative correlation between the DSQ adaptive dimension and lack of awareness (DERS). The DSQ dimension of Self Sacrificing was positively correlated with Non-acceptance of Emotional Response and Limited Access to Emotion Regulation Strategies, and less strongly but also significantly correlated with Lack of Emotional Clarity. Image Distorting style (DSQ) was significantly positively correlated with Impulse Control Difficulties and Lack of Emotional Clarity. Finally, Maladaptive style (DSQ) was positively correlated with all the DERS scales with the exception of Impulse Control Difficulties and Lack of Emotional Awareness.

\section{Factor analysis}

The exploratory factor analysis yielded 12 eigenvalues greater than 1 . The scree-plot suggested retaining the first eight factors, which accounted for $38.6 \%$ of the variance (REPR=14\%). Parallel analysis instead suggested to retain 7 factors when performing principal component analysis or 9 factors when principal axis factoring was used. In the end the 9 factors solution was choose (Table 3) since overfactoring is less dangerous than underfactoring, because it at most produced additional non meaningful factors (Crawford, Green, Levy, Lo, Scott, Svetina, \& Thompson, 2010). As may be seen from Table 3, the first seven factors were quite close to the seven first-order factors hypothesized in Fig. 1. With few exceptions, the highest loadings were on the correct factor: Factor 1: maladaptive subscales of DSQ; Factor 2: adaptive items (reappraisal dimension) of ERQ; Factor 3: maladaptive items (suppression dimension) of ERQ; Factor 4 items of DERS; Factor 5: adaptive subscales of DSQ; Factor 6: maladaptive items of CERQ; Factor 7: adaptive items of CERQ. The eighth and ninth factors were not easily interpretable. 
Table 3 Pattern matrix of the Principal axis factoring analysis (oblimin rotation)

\begin{tabular}{|c|c|c|c|c|c|c|c|c|c|c|}
\hline \multirow[t]{2}{*}{ Questionnaire } & \multirow[t]{2}{*}{ Subscale or item } & \multicolumn{9}{|c|}{ Factors } \\
\hline & & 1 & 2 & 3 & 4 & 5 & 6 & 7 & 8 & 9 \\
\hline \multirow{18}{*}{$\begin{array}{l}\text { Defense style } \\
\text { (DSQ) }\end{array}$} & (A_Affiliation) & .44 & & & & & & & & \\
\hline & A_Anticipation & & & & & -.36 & & & & \\
\hline & A_Primitive Idealization & & & & & -.28 & & & & \\
\hline & A_Task orientation & & & & & -.57 & & & & \\
\hline & A_Pseudoaltruism & & & & & -.35 & & & .22 & \\
\hline & (A_Suppression) & & & .40 & .23 & & & & & \\
\hline & A_Sublimation & & & & & -.24 & & & & \\
\hline & M_Acting out & .55 & & & & & & & & \\
\hline & ( M_Undoing) & .23 & & .42 & -22 & -.37 & & & & \\
\hline & M_Passive aggression & .43 & & & & & & & & \\
\hline & M_Consumption & .28 & & & & & & & & .21 \\
\hline & M_Fantasy & .29 & & & & & & & .27 & \\
\hline & M_Projective Identification & .30 & & & & & & & & \\
\hline & M_HelpRejecting Complaining & .31 & & .25 & & -.21 & & & & \\
\hline & M_Projection & .56 & & .36 & & & & & & \\
\hline & M_Regression & .57 & & & & & & & & \\
\hline & (M_Withdrawal) & & & & & & -.32 & & .45 & \\
\hline & M_Somatisation & .37 & & & & & & & & \\
\hline \multirow{9}{*}{ CERQ } & (M_Selfblame) & & & .24 & -.32 & & & .28 & & -.24 \\
\hline & M_Acceptance & & & & & & -.56 & & & \\
\hline & M_Rumination & & & & & & -.59 & & & \\
\hline & M_Catastrophizing & & & & & & -.65 & -.32 & -.28 & \\
\hline & (M_Blaming others) & & & & & & -.30 & & -.32 & \\
\hline & A_Positive refocusing & & .21 & & & & & .52 & & \\
\hline & A_Refocus on planning & & & & .24 & -.30 & & .42 & & \\
\hline & A_Positive reappraisal & & & & & & & .73 & & \\
\hline & A_Putting into perspective & & & & & & & .74 & & \\
\hline \multirow{10}{*}{ ERQ } & A_Thinking for increase PE & & .63 & & & & & & .21 & \\
\hline & A_ Thinking for decrease NE & & .66 & & & & & & & \\
\hline & A_Thinking about situation & & .35 & & & & & & & \\
\hline & A_ Thinking at the situation to increase PE & & .63 & & & & & & & \\
\hline & A_Control emotion by thinking & & .57 & & & & & & & \\
\hline & A_ Thinking at the situation to decrease NE & & .68 & & & & & & & \\
\hline & M_ Keep emotion myself & & & .60 & & & & & & \\
\hline & M_ Not express PE & & & .43 & & & & & & \\
\hline & M_ Control emotion by not expressing & & & .66 & & & & & & \\
\hline & M_ Not expressing NE & & .25 & .40 & & & & & & \\
\hline \multirow{6}{*}{ DERS } & M_Nonacceptance & & & & -.71 & & & & & \\
\hline & M_Difficulties Behavior & & & & -.57 & & & & & \\
\hline & M_Impulse Control Diff & & & & -.70 & & & & & \\
\hline & (M_Lack Awareness) & & & & & & & & & .63 \\
\hline & M_Limited Access to ER Strat & & & & -.74 & & & & & \\
\hline & (M_Lack Clarity) & & & & -.38 & & & & .21 & .44 \\
\hline
\end{tabular}


*loadings <.20 have been omitted; items or subscales with the highest loading on a wrong factor have been put in brackets; the prefix A and $\mathrm{M}$ refer to the classification in term of Adaptive or Maladaptive strategies ** $\mathrm{PE}=$ positive emotions; $\mathrm{NE}=$ negative emotions;

On the basis of the results presented in Table 3, 8 indicators, those with the highest loading on an unexpected factor were excluded from the subsequent confirmatory factor analysis. The firstorder confirmatory factor model displayed acceptable goodness of fit, given that only the CFI value was unsatisfactory: SB Chi-square (384) = 766.9, p < 0.001; RMSEA=0.057 (CI 90\%:0.051-0.062); $\mathrm{CFI}=0.89, \mathrm{SRMR}=0.073$ ). All the loadings (not reported here) were statistically significant at $\mathrm{p}<0.01$ with standardized values ranging between .30 and .94, except for Sublimation that was a poor indicator (standardized loading of .22), albeit statistically significant of Adaptive defense style. Factor correlations were in line with our expectation that there would be two second-order factors: as may be seen in Table 4, the adaptive dimensions of DSQ, CERQ and ERQ were highly correlated with one another and the same was true of the maladaptive dimensions of DSQ and DERS. These last two were moderately correlated with the maladaptive dimension of CERQ, while ERQ maladaptive dimension showed a statistical significant correlation only with DSQ maladaptive factor.

Table 4 Correlations between first order factors

\begin{tabular}{lcccccc}
\hline & DSQ_A & DSQ_M & CERQ_A & CERQ_M & ERQ_A & ERQ_M \\
\hline DSQ_A & 1 & & & & & \\
DSQ_M & $(.15)$ & 1 & & & & \\
CERQ_A & $\underline{.49}$ & $(-.11)$ & 1 & & & \\
CERQ_M & $(.21)$ & $\underline{.37}$ & .28 & 1 & & \\
ERQ_A & $\underline{.53}$ & $(.05)$ & $\underline{.52}$ & $(.21)$ & 1 & \\
ERQ_M & $(.10)$ & $\underline{.26}$ & $(-.04)$ & $\underline{.13)}$ & .34 & 1 \\
DERS_M & $(-.12)$ & $\underline{.55}$ & -.36 & $\underline{.23}$ & $(-.04)$ & $\underline{(.12)}$ \\
\hline
\end{tabular}

Values that are not statistically significant $(\mathrm{p}>.05)$ are reported in brackets. Correlations among adaptive and among maladaptive factors have been underlined.

DSQ_A= defense style questionnaire : adaptive dimension; DSQ_M= defense style questionnaire : maladaptive dimension; CERQ_A= cognitive emotion regulation questionnaire: adaptive dimension; CERQ_M= cognitive emotion regulation questionnaire: maladaptive dimension; ERQ_A= emotion regulation questionnaire: adaptive dimension; ERQ_M= emotion regulation questionnaire: maladaptive dimension; DERS = difficulties in emotion regulation scale.

Each of the instruments displayed a positive correlation between its own maladaptive and adaptive dimensions and for CERQ and ERQ this correlation was statistically significant. This likely flags a mild method effect, that is to say, responses are correlated because they are part of the 
same questionnaire. Also to be noted is the negative correlation found between DERS and the Adaptive subscale of CERQ, which we modelled as residual covariance in the second-order model outlined in Figure 1.

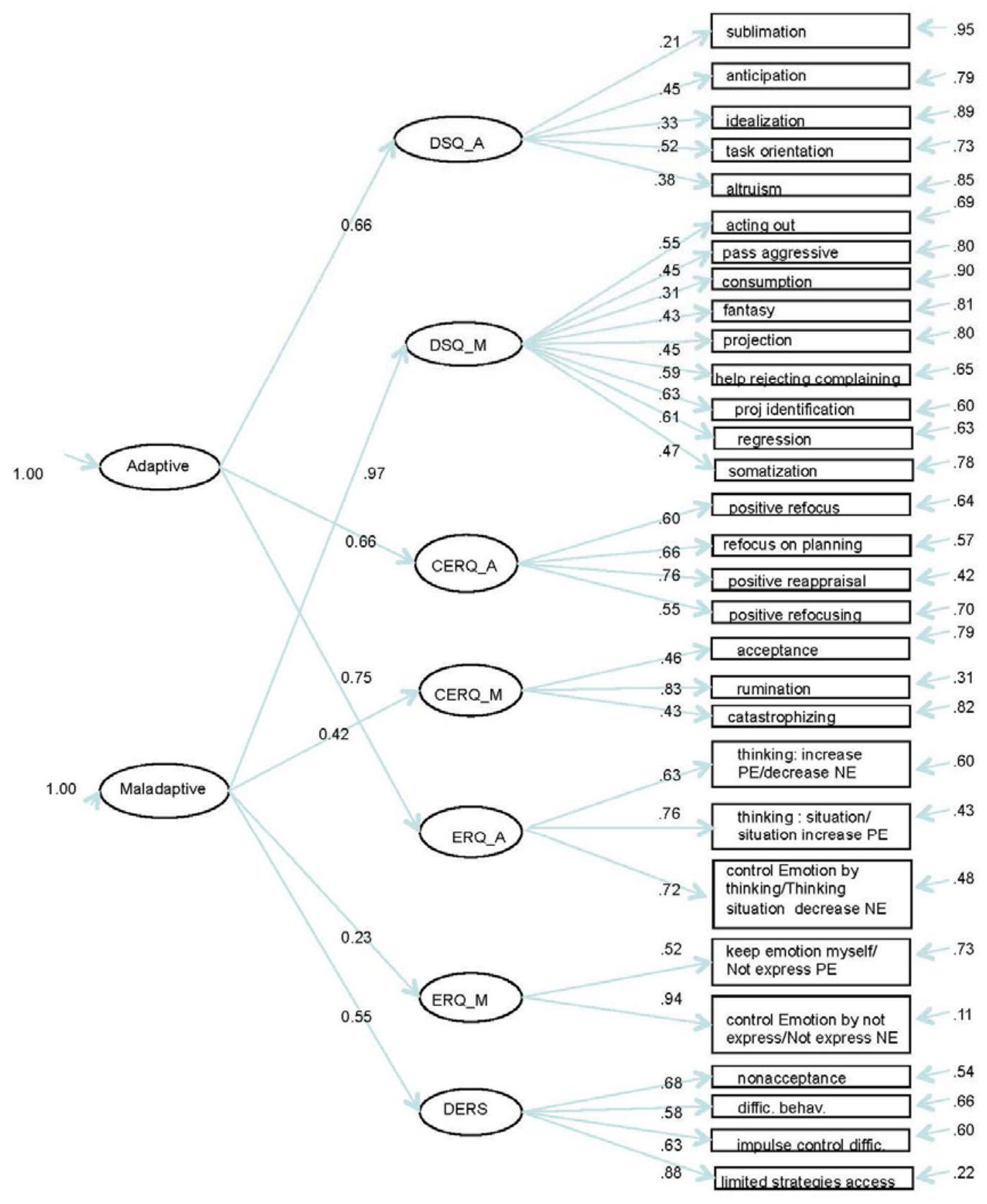


The second-order model also displayed acceptable goodness of fit; as before, only the CFI value was unsatisfactory: SB Chi-square (394) = 784.3, p < 0.001; RMSEA=0.056 (CI 90\%:0.051-0.062); $\mathrm{CFI}=0.89$, SRMR $=0.075)$. The Satorra-Bentler scaled difference chi-square test was not significant (SB-chi square difference $(10)=17.4, \mathrm{p} \cong 0.067$ ), suggesting that the hierarchical model with two second-order latent factors (adaptive and maladaptive) was acceptable.

The second-order factor solution (Figure 1) displayed the pattern of relationships reported in Table 4. The adaptive poles of the DSQ, CERQ and ERQ were good indicators of a more abstract dimension of adaptive strategies (their standardized loadings were all greater than .65). As regards the abstract dimension of maladaptive strategies, the marker was the maladaptive dimension of DSQ with a standardized loading of .97, followed by the maladaptive dimension of DERS (.55) and CERQ (.42), while the maladaptive dimensions of the ERQ was the less influenced by the abstract maladaptive dimension, with far lower, albeit statistically significant, standardized loading (.23). The covariance between the abstract dimensions of adaptive and maladaptive strategies was not statistically significant and was fixed to zero in the model presented in Figure 1.

\section{Discussion and Conclusions}

Emotion regulation and defense mechanisms, though being constructs from very different theoretical areas, appear to share some characteristics. The aim of this study was to verify if there were empirical overlapping areas between these two theoretical concepts.

The correlational analysis pointed up significant associations between the DSQ scales and the dimensions of the ERQ. As hypothesized, this indicated an association between defenses that permit awareness about feelings, represented by the Adaptive style subscale, and Cognitive Reappraisal, an emotion regulation strategy involving a rethinking of the situation. Significant correlations between the Suppression scale and the three less adaptive defensive styles confirm that the Suppression measure taps into a less effective type of emotion regulation strategy. Indeed it has been associated with impairment in memory, feelings of inauthenticity (Richards \& Gross, 2000), and poor social outcomes (Butler, Lee, \& Gross, 2007).

As predicted, correlations were found between Adaptive style (DSQ) and three of the more adaptive CERQ scales: Positive Refocusing, Refocus on Planning and Positive Reappraisal. The correlation between Self-Sacrifice and Self-Blame could be ascribed to the fact that both are related to a broader dimension that might be termed self-mortification. The negative correlation between Self Sacrificing style and Positive Reappraisal could reflect an association with the defenses involved in Self Sacrificing, such as inhibition, absence of humour and the tendency to incessantly think about the situation. The correlation between Image-Distorting style (DSQ) and 
Catastrophizing and Blaming-Others confirms the hypothesis about a link between emotion regulation scales measuring strategies of directing negative emotions against others and distorting one's perception of the situation, and defenses directed at influencing one's view of the reality, such as those implicated in the Image Distorting style.

Furthermore, the correlations between maladaptive defense style and Self-Blame, Rumination, Catastrophizing and Blaming-Others confirm that these are the least adaptive strategies assessed by the CERQ (Garnefky et al., 2002; Jermann, Van der Linden, d’Acremont, \& Zermatten, 2006). Unexpectedly, Acceptance was also weakly but positively correlated with the Maladaptive defense scale. Further studies should examine in greater depth the valence of this emotion regulation strategy.

Finally, there were significant correlations between the three DSQ scales assessing inadequate defensive styles (Maladaptive, Image Distorting and Self Sacrificing) and the scales of the DERS, while Adaptive style was only weakly correlated with Lack of Awareness, a result that may be explained by the low Cronbach's alpha value obtained for the Adaptive scale. More specifically, positive correlations were found between Self Sacrificing and all the DERS scales except Lack of Awareness and the two scales assessing behavioural control challenges (Impulse Control Difficulties and Difficulty Engaging in Goal-directed Behaviour); this may be due to the fact that a Self Sacrificing style can involve an excessive and dysfunctional level of behavioural control. Image distorting style on the other hand was only slightly positively correlated with Impulse Control Difficulties, and Lack of Emotional Clarity. In conclusion, the correlations between Maladaptive style and all the DERS scales (except for Lack of Emotional Awareness), confirm the association between difficulties in the regulation of emotion and the use of maladaptive defense mechanisms ${ }^{2}$.

Exploratory and confirmatory factor analyses were conducted to investigate whether the two abstract dimensions of adaptive and maladaptive strategies could represent a link between emotion regulation and defense mechanisms. The results of the exploratory factor analysis showed that the hypothesized classification of both emotion regulation strategies and defense mechanisms into adaptive versus maladaptive categories was empirically well-grounded. This was especially true for the subscales of the emotion regulation questionnaires and the maladaptive style subscale of the DSQ. For the DSQ adaptive style subscale, only the more strictly cognitive strategies fitted the model. Confirmatory factor analysis also supported the hypothesized linkage between emotion regulation and defense strategies, and two more abstract dimensions of adaptiveness and maladaptiveness. The second-order CFA enabled us to observe the extent to which each of the

\footnotetext{
${ }^{2}$ The correlation between mean score of all the DERS dimensions (except the Lack of emotional awareness) and the DSQ maladaptive style revealed a positive and significant correlation of .351 ( $<$.01).
} 
adaptive and maladaptive dimensions of the various questionnaires loaded on the abstract secondorder dimensions. The adaptive subscales of both the defense mechanisms and emotion regulation questionnaires had high loadings on the adaptive abstract dimension, and may therefore be taken to be good indicators of this abstract dimension which could be labelled as a general adaptive cognitive style. With regard to the maladaptive abstract dimension, only the DSQ and DERS scales heavily loaded on it. This result is not so surprising, given that in the ERQ, the maladaptive subscale includes items on suppression strategies that are not necessarily maladaptive. The same may be true of CERQ strategies such as Rumination, Catastrophizing and Acceptance.

Nevertheless, even if it may be argued that there may be circumstances under which the use of these strategies would be adaptive or not, literature clearly associated the prevalence of the use of them with negative outcomes (Garnefski, et al., 2002).

Our results underlined that these scales are not associated to the Adaptive poles, as reported in Figure 1. Moreover, Suppression (ERQ), Rumination and Catastrophizing (CERQ) resulted correlated with Image Distorting and Self Sacrificing, i.e. with mildly maladaptive defenses (DSQ; Table 2): these results suggest that ERQ and CERQ low loadings on the maladaptive factor don't mean that these strategies are adaptive, but that they are in part less maladaptive than the lack of regulation strategies (DERS) and the maladaptive defenses of DSQ.

Moreover, our results suggested that maladaptive strategies are not in opposition to adaptive strategies: few weakly negative relationship emerged from Pearson correlation analysis and only one negative relationship, that between maladaptive subscale of CERQ and DERS scale, resulted from the first order CFA. Furthermore, the two abstract dimensions of maladaptive and adaptive (second order factor) resulted not correlated. These results suggested that, coherently with recent findings (Drapeau, de Roten, Blake, Beretta, Strack, Körner, \& Despland, 2011b), non pathological people, like those of our sample, could have a repertory of defenses and emotion regulation strategies ranging from adaptive to maladaptive poles; while pathological conditions could be associated to the lack of flexibility in the use of defences and emotion regulation strategies resulting in a negative association between adaptive and maladaptive strategies. Further research on clinical samples are need to test this expectation.

This study displayed some limitations. First, the sample was not representative and its size was small. Considering the life-span development in the use of Emotion Regulation and Defense Mechanisms (Cramer, 2012; Zimmerman \& Iwanski, 2014) future studies on this topic should involve a representative sample. Moreover, given the large number of variables investigated, more subjects should be involved in follow up research. In a larger sample it would be possible to 
investigate also mildly maladaptive dimensions such as Self-sacrificing and Image-distorting not included in the CFA of this study.

Further research should deepen the study of the relationships between emotion regulation and defense mechanisms by including clinical samples and using projective tests. Moreover, describing the relationships between the two constructs permits to better clarify the definitions of the two phenomena in relation with other fields of study. For example, it can shed light on the role played by emotion regulation in clinical psychology. The position of emotion regulation in the field of clinical practice is still surrounded by debate, because of difficulties encountered in associating emotion and clinical topics, from both the conceptual and the applied point of view (Ehrenreich, Fairholme, Buzzella, Ellard, \& Barlow, 2007). A partial solution to this problem could be to identify the links between emotion regulation and defense mechanisms, a historically central construct in the field of clinical psychology, as borne out by the inclusion of defenses in the fourth edition of the Diagnostic \& Statistical Manual (DSM-IV, American Psychological Association, 1994; 2000).

In summary, the current work identified an area of overlap between emotion regulation and defense mechanisms. This is a key finding. The results of the study essentially confirm that emotion regulation and defense mechanisms are aspects of psychological functioning involving very similar phenomena.

\section{References}

Aldao, A., \& Nolen-Hoeksema, S. (2012). When are adaptive strategies most predictive of psychopathology? Journal of Abnormal Psychology, 121(1), 276-281. doi: 10.1037/a0023598

American Psychiatric Association. (1994). Diagnostic and statistical manual of mental disorders (4th ed.). Washington: Author.

American Psychiatric Association. (2000). Diagnostic and statistical manual of mental disorders (4th ed., text revision). Washington: Author.

Andrews, G., Singh, M., \& Bond, M. (1993). The Defense Style Questionnaire. Journal Of Nervous And Mental Disease, 181(4), 246-256. doi:10.1097/00005053-199304000-00006

Balzarotti, S., John, O. P., \& Gross, J. J. (2010). An Italian adaptation of the Emotion Regulation Questionnaire. European Journal of Psychological Assessment, 26(1), 61-67. doi: 10.1027/1015-5759/a000009

Bonanno, G. A. (2001). Emotion self-regulation. In J. J. Mayne, \& G. A. Bonanno (Eds.), Emotions: current issues and future directions (pp. 251-286). New York: Guilford. 
Bond, M. (2004). Empirical Studies of Defense Style: Relationships with Psychopathology and Change. Harvard Review of Psychiatry (Taylor \& Francis Ltd), 12(5), 263-278.

Bandalos, D. L., \& Finney, S. J. (2001). Item parceling issues in structural equation modeling. In G. A. Marcoulides \& R. E. Schumacker (Eds.), Advanced structural equation modeling: New developments and techniques. Mahwah, NJ: Lawrence Erlbaum Associates, Inc.

Browne, M. W., \& Cudeck, R. (1993). Alternatives ways of assessing model fit. In K. A. Bollen, \& J. S. Long (Eds.), Testing Structural Equation Models (pp. 132-162). London: Sage.

Butler, E. A., Lee, T. L., \& Gross, J. J. (2007). Emotion regulation and culture: Are the social consequences of emotion suppression culture-specific? Emotion, 7(1), 30-48. doi: 10.1037/1528-3542.7.1.30

Calkins, S. D., \& Hill, A. (2007). Caregiver influences in Emerging Emotion Regulation. In J. J. Gross (Ed.), Handbook of Emotion Regulation. New York Guilford Press.

Cramer, P. (2012). Psychological maturity and change in adult defense mechanisms. Journal of Research in Personality, 46(3), 306-316. doi: 10.1016/j.jrp.2012.02.011

Cramer, P. (2008). Seven pillars of defense mechanism theory. Social And Personality Psychology Compass, 2(5), 1963-1981. doi:10.1111/j.1751-9004.2008.00135.x

Cramer, P. (1991). The development of defense mechanisms: Theory, research, and assessment. New York, NY US: Springer-Verlag Publishing.

Crawford, A. V., Green, S. B., Levy, R., Lo, W.-J., Scots, L., Svetina, D., \& Thompson, M. S. (2010). Evaluation of Parallel Analysis Methods for Determining the Number of Factors (English). Educational and psychological measurement, 70(6), 885-901.

Diehl, M., Chui, H., Hay, E. L., Lumley, M. A., Grühn, D., \& Labouvie-Vief, G. (2014). Change in coping and defense mechanisms across adulthood: Longitudinal findings in a European American sample. Developmental Psychology, 50(2), 634-648. doi: 10.1037/a0033619

Drapeau, M., Thompson, K., Petraglia, J., Thygesen, K. L., \& Lecours, S. (2011a). Defense mechanisms and gender: An examination of two models of defensive functioning derived from the Defense Style Questionnaire. International Journal of Psychology \& Psychological Therapy, 11(1), 149-155.

Drapeau, M., de Roten, Y., Blake, E., Beretta, V., Strack, M., Körner, A., \& Despland, J.-N. (2011b). Defensive flexibility and its relation to symptom severity, depression, and anxiety. Journal of Nervous and Mental Disease, 199(1), 38-41. doi: 10.1097/NMD.0b013e3182043b4e

Ehrenreich, J. T., Fairholme, C. P., Buzzella, B. A., Ellard, K. K., \& Barlow, D. H. (2007). The role of emotion in psychological therapy. Clinical Psychology Science and Practice 14(4) 422428. doi:10.1111/j.1468-2850.2007.00102.x.

Ellison, W. D., \& Levy, K. N. (2012). Factor structure of the primary scales of the Inventory of Personality Organization in a nonclinical sample using exploratory structural equation modeling. Psychological Assessment, 24(2), 503-517. doi: 10.1037/a0026264 
English, T., \& John, O. P. (2013). Understanding the social effects of emotion regulation: The mediating role of authenticity for individual differences in suppression. Emotion, 13(2), 314329. doi: $10.1037 / \mathrm{a} 0029847$

Garnefski, N., Van Den Kommer, T., Kraaij, V., Teerds, J., Legerstee, J., \& Onstein, E. (2002). The relationship between cognitive emotion regulation strategies and emotional problems: comparison between a clinical and a non-clinical sample. European Journal of Personality, 16(5), 403-420. doi: 10.1002/per.458

Garnefski, N., Kraaij, V., \& Spinhoven, P. (2002). Manual for the use of the Cognitive Emotion Regulation Questionnaire. Leiderdorp, The Netherlands: Datec.

Gratz, K. L., \& Roemer, L. (2004). Multidimensional Assessment of Emotion Regulation and Dysregulation: Development, Factor Structure, and Initial Validation of the Difficulties in Emotion Regulation Scale. Journal of Psychopathology and Behavioral Assessment, 26(1), 41-54. doi: 0882-2689/04/0300-0041/0

Gross, J. J. (1998a). The emerging field of emotion regulation: an integrative review. Review of general psychology, 2(3) 271-299.

Gross, J. J. (1998b). Antecedent- and response-focused emotion regulation: Divergent consequences for experience, expression, and physiology. Journal of Personality and Social Psychology, 74(1), 224-237. doi: 10.1037/0022-3514.74.1.224 Gross, J. J. (2002). Emotion regulation: Affective, cognitive, and social consequences. Psychophysiology, 39(3), 281-291.

Gross, J. J., \& John, O. P. (2003). Individual differences in two emotion regulation processes: Implications for affect, relationships, and well-being. Journal of Personality and Social Psychology, 85(2), 348-362. doi: 10.1037/0022-3514.85.2.348

Gross, J. J., \& Thompson R. A., (2007). Emotion Regulation: conceptual foundations. In J. J. Gross (Ed.), Handbook of emotion regulation (pp. 33-24). New York: Guilford Press.

Hyphantis, T., Goulia, P., Floros, G. D., Iconomou, G., Pappas, A.-I., Karaivazoglou, K., \& Assimakopoulos, K. (2011). Assessing Ego Defense Mechanisms by Questionnaire: Psychometric Properties and Psychopathological Correlates of the Greek Version of the Plutchik's Life Style Index. Journal of Personality Assessment, 93(6), 605-617. doi: 10.1080/00223891.2011.608759

Hu, L., \& Bentler, P. M. (1995). Evaluating model fit. In R. H. Hoyle (Ed.), Structural equation modelling: Concepts, issues, and applications (pp. 76-99). Thousand Oaks, CA: Sage.

Hu, L., \& Bentler, P. M. (1999). Cutoff criteria for fit indexes in covariance structure analysis: Conventional criteria versus new alternatives. Structural Equation Modeling, 6, 1-55.

Jermann, F., Van der Linden, M., d'Acremont, M., \& Zermatten, A. (2006). Cognitive Emotion Regulation Questionnaire (CERQ): Confirmatory factor analysis and psychometric properties of the French translation. European Journal of Psychological Assessment, 22(2), 126-131. doi: 10.1027/1015-5759.22.2.126

Jöreskog, K. G., \& Sörbom, D. (1996a). LISREL 8: User's reference guide. Chicago: Scientific Software International. 
Koole, S. L. (2009). The psychology of emotion regulation: an integrative review. Cognition and emotion, 23(1), 37. doi: 10.1080/02699930802619031

Lingiardi, V., Madeddu, F. (2002). I meccanismi di difesa. Teoria clinica e ricerca empirica.[The defense mechanisms. Clinical theory and empirical research] Raffaello Cortina: Milano.

Martini, P. S., Roma, P., Sarti, S., Lingiardi, V., \& Bond, M. (2004). Italian version of the Defense Style Questionnaire (English). Comprehensive psychiatry, 45(6), 483-494.

Molinengo, G., \& Testa, S. (2010). Analysis of the psychometric properties of an assessment tool for deviant behavior in adolescence. European Journal of Psychological Assessment, 26(2), 108-115. doi: 10.1027/1015-5759/a000015

Nunnally, J. C., \& Bernstein, I. H. (1994). Psychometric theory (3rd ed.). New York: McGrawHill.

O'Connor, B. P. (2000). SPSS and SAS programs for determining the number of components using parallel analysis and Velicer's MAP test. Behavior Research Methods, Instrumentation, and Computers, 32, 396-402.

Perry, J. C. (1990). Defense Mechanisms Rating Scale. $5^{\text {th }}$ edition. In Lingiardi, V., Madeddu, F. (Eds.) I meccanismi di difesa. Teoria clinica e ricerca empirica. .[The defense mechanisms. Clinical theory and empirical research] Milano: Raffaello Cortina.

Richards, J. M., \& Gross, J. J. (2000). Emotion regulation and memory: The cognitive costs of keeping one's cool. Journal of Personality and Social Psychology, 79(3), 410-424. doi: 1O.1037/70O22-3514.79.3.410

Ruuttu, T., Pelkonen, M., Holi, M., Karlsson, L., Kiviruusu, O., Heilä, H., . . . Marttunen, M. (2006). Psychometric properties of the Defense Style Questionnaire (DSQ-40) in adolescents. Journal of Nervous and Mental Disease, 194(2), 98-105. doi: 10.1097/01.nmd.0000198141.88926.2e.

Segal, D. L., Coolidge, F. L., \& Mizuno, H. (2007). Defense mechanism differences between younger and older adults: A cross-sectional investigation. Aging \& Mental Health, 11(4), 415-422. doi: 10.1080/13607860600963588

Sala, M. N., Molina, P., Abler, B., Kessler, H., Vanbrabant, L., \& van de Schoot, R. (2012). Measurement invariance of the Emotion Regulation Questionnaire (ERQ). A cross-national validity study. European Journal of Developmental Psychology, 9(6), 751-757.

Satorra, A., \& Bentler, P. M. (2001). A scaled difference chi-square test statistic for moment structure analysis (English). Psychometrika, 66(4), 507-514.

Thompson, R. A. (1994). Emotion regulation: A theme in search of definition. Monographs of the Society for Research in Child Development, 59(2-3), 25-52, 250-283. doi: 10.2307/1166137

Watson, D. C., \& Sinha, B. K. (1998). Gender, age, and cultural differences in the Defense Style Questionnaire-40 (English). Journal of Clinical Psychology, 54(1), 67-75.

Westen, D., \& Blagov, P. S. (2007). A clinical-empirical model of emotion regulation: From defense and motivated reasoning to emotional constraint satisfaction. In J. J. Gross (Ed.), Handbook of emotion regulation (pp. 373-392). New York: Guilford Press. 
Vaillant, G. E. (1994). Ego mechanisms of defense and personality psychopathology. Journal Of Abnormal Psychology, 103(1), 44-50.

Yu, C. (2011). The mechanisms of defense and dreaming. Dreaming, 21(1), 51-69. doi:10.1037/a0022867

Zimmermann, P., \& Iwanski, A. (2014). Emotion regulation from early adolescence to emerging adulthood and middle adulthood: Age differences, gender differences, and emotion-specific developmental variations. International Journal of Behavioral Development, 38(2), 182194. doi: $10.1177 / 0165025413515405$ 